\title{
Preface to the special issue in memory of S. Barry Cooper (1943-2015)
}

\author{
Benedikt Löwe \\ Institute for Logic, Language and Computation, Universiteit van Amsterdam, Postbus 94242, 1090 GE Amsterdam, The Netherlands \\ Fachbereich Mathematik, Universität Hamburg, Bundesstraße 55, 20146 Hamburg, Germany \\ Churchill College \& Faculty of Mathematics, University of Cambridge, Storey's Way, Cambridge, CB3 0DS, England
}

On 26 October 2015, Barry Cooper passed away: he was the heart and soul of the Association Computability in Europe and the driving force behind this journal. When other members of the Association were sceptical about the need and sustainability of the planned journal Computability, he remained committed to it and insisted on the importance of launching the journal during the Turing Centenary 2012. As often, it turned out that Barry was right: as the readers of this journal can surely attest, the journal is a success. Therefore, it is a truly appropriate homage to Barry that this first special issue of the journal Computability is published in memory of the person without whom the journal would not exist. Barry's contribution to the history of the Association was remembered in [1], published in this journal; with this special issue, his friends, colleagues and collaborators honour his life and work.

The special issue contains an obituary, composed of six parts, written independently by different authors, which highlight various aspects of Barry's life and work from different angles and is illustrated by many pictures.

The mathematical substance of this special issue consists of nine mathematical papers, falling into three different categories:

(a) Papers to which Barry contributed himself but which could not be published earlier; these include the papers Splitting and jump inversion in the Turing degrees by Cooper, Li, \& Xia and Linearisations and the Ershov hierarchy by Cooper, Gay, Harris, Lee, \& Morphett.

(b) Papers co-authored by Barry's doctoral students; these include the papers Pointed computations and MartinLöf randomness by Barmpalias, Lewis-Pye, \& Li, The jump hierarchy in the enumeration degrees by Ganchev \& Soskova and The search for natural definability in the Turing degrees by Lewis-Pye. The last paper in this category is an expository article that came out of a course taught by Lewis-Pye at the University of Notre Dame in 2010, covering topics of great interest to Barry.

(c) Papers by friends and collaborators of Barry's; these include the papers Automorphism bases for the recursively enumerable degrees by Ambos-Spies, A probabilistic anytime algorithm for the halting problem by Calude and Dumitrescu, Finitely generated semiautomatic groups by Jain, Khoussainov, \& Stephan, and Extending Cooper's theorem to $\Delta_{3}^{0}$ Turing degrees by Selivanov and Yamaleev.

With these mathematical contributions, the authors pay tribute to Barry's input to the mathematical theory of computability. Of course, Barry's interests, especially in the last decade, were considerably wider than that: he believed that Computability is one of the fundamental concepts of the world and should be seen in a triad together with Nature and Science. The scope of this journal and of the conference series Computability in Europe, reaching out well beyond mathematics and theoretical computer science to research in the natural sciences, philosophy and history, can be seen as the reflection of Barry's belief in the fundamentality of Computability.

\section{References}

[1] B. Löwe, Barry Cooper (1943-2015): The engine of computability in Europe, Computability 5(1) (2016), 3-11. doi:10.3233/COM-160052. 